\title{
LÍNGUA INGLESA PARA A TERCEIRA IDADE NA UFCG
}

\author{
Douglas Keusley ${ }^{1}$ \\ Https://orcid.org/0000-0003-3859- 2366 \\ JOYCE LUNA ${ }^{2}$ \\ Https://orcid.org/0000-0002-3544-3560 \\ NeIDE CRUZ ${ }^{3}$ \\ https://orcid.org/0000-0003-1165-3253
}

Resumo: Este artigo relata a experiência realizada a partir de dois projetos de extensão desenvolvidos em dois anos consecutivos, 2017 e 2018, na Universidade Federal de Campina Grande denominados 'Ensino de língua inglesa para a terceira idade - Anos I e II. Os projetos ofereceram atividades de língua inglesa para a terceira idade, tendo como órgão parceiro o PIATI, Programa Interdisciplinar de Apoio à Terceira Idade, que atua na UFCG há 15 anos. O público alvo é composto por adultos com idades variando entre 60 e 78 anos. Os princípios da abordagem comunicativa, que priorizam a comunicação através de interações na língua estrangeira, considerando situações reais e de interesse dos alunos, subjazem os materiais didáticos utilizados e a metodologia seguida durante a realização das atividades. Esses materiais foram planejados, elaborados pelos dois bolsistas que ministraram as atividades. Os resultados revelam que os objetivos do projeto foram alcançados.

Palavras-chave: Terceira idade. Língua inglesa. Atividades.

\section{ENGLISH LANGUAGE FOR THE ELDERLY AT UFCG}

Abstract: This article reports on the experience of two extension projects developed in two consecutive years, 2017 and 2018, at the Federal University of Campina Grande, called 'English Language for the Elderly - Years I and II. The projects offered English language activities for

1 Aluno do curso de Letras/Inglês da Universidade Federal de Campina Grande. E-mail: douglasjahv@gmail.com

2 Aluna do curso de Letras/Inglês da Universidade Federal de Campina Grande. E-mail: joyce. luna.8@gmail.com

3 Doutora e pós-doutora em Inglês : Estudos linguisticos e literários. Professora do curso de Letras/ Inglês da Universidade Federal de Campina Grande. E-mail: neidecruz@uol.com.br 
the elderly, with PIATI, the Interdisciplinary Support Program for the Elderly, which has been working at the UFCG for 15 years. The target audience consists of adults ranging from 60 to 78 years old. The principles of the communicative approach, which prioritize communication through interactions in the foreign language, considering real situations and interest of the students, underlie the didactic materials used and the methodology followed during the accomplishment of the activities. These materials were planned and prepared by the two students who applied the activities. The results reveal that the projects objectives have been achieved.

Keywords: The elderly. English Language. Activities

\section{LENGUA INGLESA PARA LA TERCERA EDAD EN LA UFCG}

Resumen: Este artículo relata la experiencia realizada a partir de dos proyectos de extensión desarrollados en dos años consecutivos, 2017 y 2018, en la Universidad Federal de Campina Grande, denominados 'Lengua inglesa para la tercera edad - Años I y II'. Los proyectos ofrecieron actividades de lengua inglesa para la tercera edad, teniendo como órgano socio el PIATI, Programa Interdisciplinario de Apoyo a la Tercera Edad, que actúa en la UFCG hace 15 años. El público está compuesto por adultos con edades que varían entre 60 y 78 años. Los principios del enfoque comunicativo, que priorizan la comunicación a través de interacciones en la lengua extranjera, considerando situaciones reales y de interés de los alumnos, subyace los materiales didácticos utilizados y la metodología seguida durante la realización de las actividades. Estos materiales fueron planificados, elaborados por los dos becarios que ministraron las actividades. Los resultados revelan que se han alcanzado los objetivos del proyecto.

Palabras clave: La tercera edad. Lengua inglesa. Actividades.

Submetido em: 16/12/2018

Aceito em: 21/12/2018

\section{INTRODUÇÃO}

O número de falantes de inglês tem crescido continuamente no mundo (JENKINS, 2000; SEILHOFER, 2004; WALKER, 2010), e a consequente utilização do inglês como língua de comunicação internacional tem ocasionado o interesse pelo seu aprendizado em diferentes faixas etárias (ROCHA; BASSO, 2008), incluindo pessoas da terceira idade. Além disso, estudos têm sido realizados, a fim de compreender a construção da aprendizagem do inglês nesta etapa da vida (CONCEIÇÃO, 2000; PIZZOLATTO, 2008). Esses estudos demonstram que aprender uma língua estrangeira na terceira idade é uma realidade, e pode proporcionar uma integração social benéfica para os participantes. Considerando esse contexto, dois projetos de extensão, denominados 'Ensino de língua inglesa para a terceira idade' e 'Ensino de língua 
para a terceira idade - Ano II' foram desenvolvidos consecutivamente durante os anos de 2017 e 2018 na Universidade Federal de Campina Grande (PROBEX-2017/UFCG e PROBEX/2018/UFCG).

As metas dos projetos foram: (1) Oferecer às pessoas da terceira idade oportunidade de aprender informações novas e de melhorar a capacidade intelectual e cultural; (2) Proporcionar ao público da terceira idade oportunidade de melhoria da sua qualidade de vida.

\section{OBJETIVOS}

Apresentamos como objetivo geral: Desenvolver a competência comunicativa na língua inglesa de pessoas da terceira idade, além de oferecer a essas pessoas uma oportunidade de inserção social. Os objetivos específicos incluem: (1) Oferecer aos participantes espaços para interagirem em inglês, através de atividades e situações de interesse real para cada um; (2) Praticar as habilidades de produção e compreensão oral; e (3) Elaborar materiais específicos para o grupo de participantes, utilizando atividades lúdicas, músicas e filmes, não somente para a apropriação dos conteúdos linguísticos, mas também como fator motivacional.

No ano de 2017, atividades que envolvem o desenvolvimento da habilidade de produção oral foram as mais desenvolvidas, uma vez que, através de um questionário de necessidades aplicado no primeiro encontro, os participantes revelaram, principalmente, o desejo de aprender a conversar e a interagir em inglês ${ }^{4}$. Em 2018, a fim de ampliar o projeto, além da produção oral, atividades que envolvem a habilidade de compreensão oral foram incluídas e desenvolvidas no Laboratório de Línguas da UAL. O referido Laboratório possui 01 computador e 24 cabines individuais com fones e painel de áudio, onde cada usuário tem a oportunidade de ouvir os áudios liberados pelo computador. Como a escuta é individual, cada um tem a oportunidade de ouvir os áudios várias vezes, de acordo com o seu ritmo.

Os projetos foram desenvolvidos entre os meses de maio a dezembro de 2017 e de 2018.

4 A experiência realizada no ano de 2017 foi relatada no X Seminário Nacional sobre Ensino de Língua Materna, Estrangeira e de Literaturas, na categoria Painel. 


\section{METODOLOGIA}

Durante as duas vigências do projeto, encontros semanais eram realizados entre a coordenadora e orientadora do projeto, professora do curso de Letras/Inglês da UAL, e os dois bolsistas, alunos do curso de Letras/Inglês, que ministraram as atividades. As reuniões eram realizadas, a fim de alcançar os seguintes objetivos: (1) Discutir aspectos relacionados às três áreas que embasam teoricamente o projeto: (1.1) aquisição de línguas estrangeiras; (1.2) ensino-aprendizagem de línguas estrangeiras na terceira idade; e (1.3) abordagem comunicativa; (2) Planejar as atividades didático-pedagógicas que seriam realizadas; e (3) Elaborar as sequências didáticas a serem aplicadas.

Os temas das leituras e discussões incluídas no objetivo referem-se à Hipótese do Período Critico (CELCE-MURCIA, 2010; ELLIS, 2000), Estratégias de Aprendizagem (OXFORD, 2000), particularmente Estratégias de Aprendizagem por alunos da Terceira Idade (CONCEIÇÃO, 2005) e Princípios da Abordagem Comunicativa (NUNAN, 2006; SAVIGNON, 2007; ALMEIDA FILHO, 2007).

Quatro etapas foram seguidas para alcançar os objetivos (2) e (3). Primeiro, decidíamos os temas que seriam abordados e desenvolvidos durante as atividades. Segundo, os bolsistas planejavam as atividades didático-pedagógicas e as sequências didáticas que seriam realizadas, focalizando os temas selecionados. Terceiro, a viabilidade de realização das atividades e sequências didáticas eram discutidas, e alterações, se necessário, eram feitas. Finalmente, os materiais para aplicação das atividades e sequências didáticas eram confeccionados.

\section{ABORDAGEM COMUNICATIVA}

Os princípios teóricos da abordagem comunicativa, que se baseia na concepção sócio-interacionista de língua, fundamentaram as atividades e nortearam o planejamento e a elaboração dos materiais utilizados. A referida abordagem, que tem sido discutida amplamente em nível internacional (RICHARDS; RODGERS, 2004; NUNAN, 2006; SAVIGNON, 2007) e também no Brasil (ALMEIDA FILHO, 2007), focaliza os aspectos sociais da linguagem e o uso efetivo da língua. O princípio fundamental é desenvolver no aprendiz a competência comunicativa: conceito educacional, que "permite ao falante saber o que falar e como falar com quaisquer interlocutores em quaisquer circunstâncias" (BORTONI-RICARDO, 2008, p. 39). A competência 
comunicativa possui quatro dimensões: (1) competência gramatical; (2) competência sociolinguística; (3) competência discursiva; e (4) competência estratégica. Essas competências, de acordo com Savignon (2007), são descritas da seguinte forma:

- gramatical - refere-se à habilidade em utilizar o léxico, a sintaxe e a fonologia da língua;

- sociolinguística - considera o papel que os participantes assumem na interação;

- discursiva - diz respeito às noções de coerência e coesão, à interconexão de orações e frases para formar um todo significativo; e

- estratégica - relaciona-se às estratégias utilizadas pelo falante para suprir o conhecimento limitado na língua estrangeira.

Adotamos a abordagem comunicativa como base teórica na elaboração das atividades, uma vez que o uso efetivo da língua focalizado pela mesma tem sido reconhecido como aspecto motivador.

\section{PARTICIPANTES}

Os participantes eram tanto do sexo masculino como do feminino, e as idades variavam entre 60 e 78 anos de idade. Alguns formavam casais. As profissões são variadas: professores universitários, contadores, funcionários públicos, comerciantes, enfermeira.

\section{ATIVIDADES}

Apresentaremos, a seguir, um resumo de duas atividades aplicadas. A primeira focaliza o desenvolvimento da habilidade de produção oral, a qual foi aplicada no ano de 2017. A segunda prioriza a habilidade de compreensão oral, aplicada no ano de 2018.

\section{Atividade 1 - Produção oral}

Tema - preferências cinematográficas

Recursos e materiais utilizados - data show, slides e computador, marcador de quadro branco. 
Descrição - Antes de dar início à temática, pedimos que os participantes assistissem ao curta-metragem Presto $(2008)^{5}$, com duração de cinco minutos, que não contém diálogos. Selecionamos o referido curta, uma vez que o objetivo da atividade era discutir e expressar preferências sobre filmes, a partir de vocabulário previamente apresentado. Caso contivesse diálogos, os participantes poderiam atentar para o vocabulário contido no curta, e desviar a atenção do real objetivo da atividade. Ao término do curta, perguntamos se os participantes tinham gostado e sugerimos que os mesmos utilizassem o vocabulário sobre preferências - "Enjoy", "Like", "Hate" e "Love”. Solicitamos que informassem o gênero do filme apresentado, e, em seguida, que exemplificassem outros tipos de filme, se possível, em inglês. Anotamos os exemplos no quadro e adicionamos nomes de outros gêneros, por exemplo, "Romance", "Action", "Horror", "Sci-fi". Pedimos que eles descrevessem os gêneros anotados no quadro, dando uma característica positiva e uma negativa para cada um, e logo após explicamos qual era o equivalente do adjetivo em inglês. Em seguida, solicitamos que os alunos formassem duplas, e que discutissem com seu/sua parceiro(a) sobre um ou dois gêneros, expressando suas opiniões (se gostam ou não, e por quê). Sugerimos, também, que, mencionassem as preferências de alguém da família.

Atividade 2 - Compreensão oral

Tema - Cenas do filme 'Friends'

Recursos e materiais utilizados - data show, slides e computador, marcador de quadro branco, equipamentos do Laboratório de Línguas (computador e cabines individuais com fones e painel de áudio) . Descrição - Usamos 3 cenas de um episódio da série "Friends", em sequência. A escolha de 'Friends' foi motivada pelo desejo que os participantes da terceira idade revelaram de assistir uma série e entender o que está sendo dito sem a utilização de legendas. A técnica adotada para a atividade foi a seguinte: treinar inicialmente a compreensão da fala dos personagens em áudio apenas, separada do visual, para, em seguida, os dois recursos, áudio e vídeo, serem usados em conjunto. As três cenas fazem parte do mesmo episódio, porém com problemas e personagens diferentes. Quatro passos foram seguidos na apresentação e discussão de cada uma:

$5 \quad<$ https://www.youtube.com/watch? ?=D4Dnm6dkOVI\&t=31s $>$ Acesso em: 04/11/2017 
Passo 1 - colocamos apenas o áudio utilizando os recursos do laboratório, onde cada participante tinha um fone de ouvido a sua disposição, isolando sons externos e proporcionando maior concentração. Os participantes ouviam o áudio três vezes, tentando escrever palavras que compreendiam (quaisquer que fossem) e deduzir o máximo de informações possíveis (onde acontece a cena, com quantas pessoas, qual o sentimento de cada personagem, etc).

Passo 2: entregamos uma atividade apresentando as falas dos personagens com lacunas a serem preenchidas. Deixamos o áudio livre por dez minutos para que os participantes pudessem pausar e ouvir individualmente em suas cabines quantas vezes quisessem ou precisassem, a fim de completar a atividade.

Passo 3: discutimos e explicamos os significados das falas, até que pudessem compreender tudo o que estava sendo dito. A leitura das falas também era feita.

Passo 4: assistimos a cena completa com o visual três vezes, incluindo e excluindo a legenda.

Acreditamos que essa atividade possibilitou aos participantes desfrutarem de um desejo de longa data, como mencionado anteriormente, de assistir uma série ou filme e entender o que está sendo dito sem a utilização de legendas. Reconhecemos que foi uma pequena amostra, porém, atestamos sua possibilidade.

\section{AVALIAÇÃO}

Os projetos foram avaliados com os alunos/bolsitas e com os participantes da terceira idade.

Avaliação com os alunos/bolsistas - as avaliações ocorriam semanalmente de acordo com as metas e objetivos estabelecidos, através das reuniões entre a coordenadora e os bolsistas. Quatro critérios foram adotados para avaliação dos bolsistas: (1) o nível de interesse dos mesmos; (2) a desenvoltura na ministração das atividades; (3) a criatividade na produção do material que seria aplicado com o público da terceira idade; e (4) a assiduidade e a pontualidade de cada um.

Avaliação com o público da terceira idade - tencionando avaliar os efeitos e resultados das atividades aplicadas, solicitamos aos participantes, ao final dos anos de 2017 e de 2018, que respondessem oralmente a seguinte pergunta? O 
que as atividades de língua inglesa têm representado/representam para você? As respostas foram gravadas em áudio ${ }^{6}$. Identificamos três aspectos recorrentes nos dados fornecidos, descritos, a seguir.

(1) Inserção social e familiar - A maioria dos participantes demonstrou estarem inseridos socialmente, como mostra o excerto a seguir?

representa pra mim integração, conhecimentos, novas amizades, e... uma interação total entre os colegas e os professores. e uma visão nova de... de inglês, que a gente vê as palavras por aí e não sabe nem traduzir, mas a gente já fica interessado no que é que significa. vai procurar, vai buscar.

Como mostrado no excerto, além de as atividades terem proporcionando aos participantes novas amizades, também os auxilia a se tornarem membros ativos na sociedade, uma vez que a língua inglesa tem sido utilizada amplamente no comércio, em anúncios e nas novas tecnologias. Percebemos, então, que as atividades estão respondendo às necessidades que os participantes têm de entenderem esse inglês. A inserção familiar foi particularmente exemplificada por uma aluna:

cada dia tô mais...querendo aprender mais, tô mais empolgada ainda né, em aprender... tanto que eu fico com meu neto né que ele tá fazendo [inglês]...ai fica eu com ele 'O que é que você aprendeu hoje?'...ai ele chega 'Vovó o que você aprendeu?

Essa participante demonstra uma satisfação e um orgulho em poder se comunicar e se aproximar do neto, que faz parte de outra geração, tendo como assunto motivador as atividades de inglês que ela está participando.

(2) Apropriação dos conteúdos - O excerto, a seguir, revela que os conteúdos ministrados estão sendo apreendidos pelos participantes:

hoje já tenho uma grande diferença, antes eu ouvia, por exemplo, uma música e não conseguia identificar quase nada, hoje eu já consigo identificar muita coisa, já consigo pegar a letra de uma música, acompanhar.

A resposta da participante revela que as atividades realizadas estão realmente auxiliando-a a melhorar seus conhecimentos do inglês.

6 Todos os participantes autorizaram a inclusão de suas respostas neste artigo.

7 ...representa pausa; , entoação ascendente; . entoação descendente 
(3) melhoria da habilidade de compreensão oral - os comentários dos participantes referem-se principalmente ao uso dos equipamentos do laboratório, tais como fones de ouvido com cabines individuais, os quais facilitaram a compreensão:

Olha, facilita muito com essa utilização desse equipamento, facilita a compreensão. E eu gostei muito de vir aqui para o laboratório, porque eu acho que a gente aprende mais, facilita.

(4) Atuação dos bolsistas - todos os participantes fizeram comentários a respeito da atuação dos professores/bolsistas:

Os alunos (bolsistas) são excelentes, tem uma paciência muito grande conosco.

O excerto representa uma resposta importante relacionada à atuação dos professores em formação inicial no projeto. Inicialmente, os mesmos ficavam preocupados com a quantidade de conteúdos e atividades que iriam ministrar. No entanto, perceberam que mais importante seria o respeito que teriam que ter ao ritmo de aprendizagem dos participantes. Nos primeiros encontros, os participantes comentavam que tinham receio de não conseguirem aprender, por causa da idade. Isso fez com que os bolsistas atuassem de forma paciente na ministração das atividades, respeitando as dificuldades de cada um. As explicações eram repetidas, quantas vezes fossem necessárias. Entendemos que essa é uma característica peculiar do grupo da terceira idade, e a preocupação em incluir conteúdos passou a ser secundária. O mais importante era ouvir os participantes e as suas necessidades.

\section{CONSIDERAÇÕES FINAIS}

Considerando os resultados apresentados, entendemos que os objetivos dos projetos, mencionados na introdução, foram alcançados. Destacamos aqui dois desdobramentos dos projetos. O primeiro está relacionado à possibilidade de compilarmos os materiais elaborados para as atividades em forma de revista ou livro. $\mathrm{O}$ segundo diz respeito à continuação do projeto nos anos seguintes, já que esse aspecto foi mencionado pelos participantes ao responderem a pergunta solicitada para termos dados sobre o resultado do projeto, 
apresentados no item 6. Concluímos este artigo com a voz de uma das participantes a esse respeito:

desde já eu gostaria que o curso fosse continuado. É muito importante pra gente.

\section{REFERÊNCIAS}

ALMEIDA FILHO, J. C. P. Linguística aplicada, ensino de línguas \& comunicação. Campinas: Pontes, 2007.

BORTONI-RICARDO, S. M. O professor pesquisador: Introdução à pesquisa qualitativa. São Paulo: Parábola editorial, 2008.

CONCEIÇÃO, M. Estratégias de aprendizagem e o desafio de aprender uma língua estrangeira na terceira idade. Letras \& Letras, v. 21, n. 1, p, 195-218, 2005.

JENKINS, J. The phonology of English as an International Language. Oxford: Oxford University Press, 2000.

NUNAN, D. Designing tasks for the communicative classroom. Cambridge: Cambridge University Press, 2006.

PIZZOLATTO, C. E. A sala de aula de língua estrangeira com adultos da terceira idade. In: ROCHA, Cláudia; BASSO, Edcleia. Ensinar e aprender língua estrangeira nas diferentes idades: reflexões para professores e formadores. São Carlos: Editora Claraluz, 2008. p. 237-255.

RICHARDS, J.; RODGERS, T. Approaches and methods in language teaching. Cambridge: Cambridge University Press, 2004.

ROCHA, C.; BASSO, E. Ensinar e aprender língua estrangeira nas diferentes idades: reflexões para professores e formadores. São Carlos: Editora Claraluz, 2008.

SAVIGNON, S. Beyond communicative language teaching: what's ahead? Journal of Pragmatics, v. 39, n. 1, 2007. pp. 207-220.

SEILDHOFER, B. Research perspectives on teaching English as a lingua franca. In:Annual Review of Applied Linguistics, 24, 2004. pp. 209-239.

WALKER, R. Teaching the pronunciation of English as a Lingua Franca. Oxford: Oxford University Press, 2010. 